\title{
A dependência dos adolescentes ao mundo virtual ${ }^{*}$
}

\author{
Bruna Goudinho Gonçalves ${ }^{l}$ \\ Denise Nuernberg ${ }^{2}$ \\ Universidade do Extremo Sul Catarinense
}

\begin{abstract}
O presente artigo trata-se de um estudo de campo do tipo exploratório, qualitativo realizado com 10 adolescentes voluntários (cinco do sexo feminino e cinco do sexo masculino) de uma escola de Criciúma/SC. Para a coleta dos dados utilizou-se um questionário contendo dez perguntas, no qual procurou-se verificar a adicção dos adolescentes no mundo virtual e como este pode influenciar na vida social destes adolescentes. Salienta-se que é no período da adolescência que se constrói a identidade e a autonomia, como também ocorrem mudanças físicas e emocionais, mas com a utilização frequente da internet, pode ocorrer um comprometimento da interação social. Diante disso, concluise, a partir da análise dos dados que a internet potencializa a onipotência juvenil e se seguir neste contexto, vários adolescentes necessitarão de auxílio terapêutico. Este estudo contribui com esta temática tão importante e ainda pouco fundamentada.
\end{abstract}

Palavras Chave: Vício na internet-Rede social - Adolescência.
This article is a field study type exploratory, qualitative with 10 volunteers adolescents (five female and five male) from a school of Criciúma/SC, for data collection used a questionnaire with ten questions, in which look to verify the addiction of adolescents in the virtual world and how the addiction can influence in the social life of adolescents. Accentuate that is during adolescence that is constructed the identity and autonomy, as well physical and emotional changes occur, but with the utilization in frequency of internet can implicate the social interaction. Given this it is concluded that it was realized with the analysis of the data that the internet enhances the omnipotence of youth and if followed in this context, several teenagers required the aid of therapy. This study will contribute with this theme so important and poorly reasoned.

Keywords: Addiction on the internet Social networking - Teenagers.

\section{Introdução}

$\mathrm{O}$ universo virtual é, talvez, o espaço de maior interação entre as pessoas, visto que atualmente, estão ficando mais tempo interagindo na internet,

\footnotetext{
* The dependence of teenagers by the virtual world

${ }^{1}$ Graduação em Psicologia, Universidade do Extremo Sul Catarinense. Endereço para correspondências: Rua Sete de Setembro, número 110, Apto. 1203, Criciúma, SC (brunasgon@bol.com.br).

${ }^{2}$ Coordenadora do Curso de Graduação em Psicologia, Universidade do Extremo Sul Catarinense. Endereço para correspondências: Rua Cel. Pedro Benedet, número 363, Sala 809, Criciúma, SC (deniseunesc@gmail.com).
} 


\section{HUM ANAS}

e que o número de computadores pessoais tem aumentado, a cada dia no Brasil, com isso novos problemas sociais e comportamentais surgem diante desse novo cenário.

Diante do exposto, o presente artigo questiona sobre a atualidade do ciberespaço e suas consequências, partindo do pressuposto que essa nova interface, internet e interação humana tragam novos procedimentos que precisam ser investigados, haja vista que foi fundado a primeira clínica no mundo, para crianças e adolescentes com dependência no uso do computador, localizada na Inglaterra.

Constata-se no mundo virtual, um significativo crescimento dos meios de comunicação, e em um curto espaço de tempo se desenvolveram ferramentas para bate-papos virtuais muito avançadas, além dos blogs que facilitaram muito a interação das pessoas no ciberespaço.

Esses locais virtuais possibilitam ao usuário trocar informações com várias outras pessoas de muitos lugares do mundo ao mesmo tempo. Alguns destes tornaram as conversas virtuais mais atrativas, devido aos novos recursos de entretenimento disponibilizados. Emotions, sons, vídeos, jogos, postagem de fotos, despertaram a curiosidade dos jovens. Essa tecnologia, que disponibiliza, além da conversa digital, o som e a imagem em tempo real da outra pessoa com quem o usuário está interagindo, tornou-se uma diversão para os jovens, substituindo, muitas vezes, o contato físico.

Hoje em dia é comum deparar-se com pessoas que não conseguem mais conviver apenas com a realidade comum, pois estão inseridas nos espaços virtuais e, muitas vezes, dependentes das opções que o mundo virtual pode lhes oferecer. Segundo Schwartz (2005 apud NARDON, 2006), a internet está, cada vez mais, presente no cotidiano das pessoas, principalmente na vivência dos jovens.

Destaca-se que isso ocorre porque a internet possibilita a criação de um mundo paralelo, ou seja, é vivenciado o mundo virtual (chamado ciberespaço), no qual é possível vivenciar experiências que só eram imaginadas em histórias de ficção científica (entre outros), e o mundo real, a realidade em que vive. Dessa forma, podem ocorrer alterações nas relações sociais dos jovens.

Evidencia-se também, que o mundo virtual tem conseguido mobilizar segmentos sociais de uma maneira mais crítica e com isso esses movimentos individuais e coletivos que nasceram no ciberespaço, já se estabelecem como uma cultura muito além de uma pequena diversão para os jovens na frente do computador.

Por conseguinte, identifica-se a relevância desse estudo no sentido de contribuir com a sociedade no melhor entendimento sobre a dependência na internet e suas consequências na vida das pessoas. 


\section{A dependência dos adolescentes ao mundo virtual B.G. Gonçalves \& D. Nuernberg}

\section{A adolescência}

De acordo com Gregg e Shale (2003), atualmente a adolescência em alguns casos segundo pesquisa realizada nos Estados Unidos e Grã-Bretanha, começa aos oito anos e, o jovem sai da casa dos pais, após os 25 anos. Segundo Papalia, Olds e Feldman (2009), é neste período que muitas mudanças e transformações físicas e emocionais acontecem na pré-adolescência, se estendendo mais ou menos até o ingresso nas responsabilidades da vida adulta. Para Zagury (2002), as meninas amadurecem mais cedo, por volta dos dez anos e os meninos por volta dos treze anos, indo até os 19, 20 ou até mesmo 21 anos, em alguns casos. Sendo essa uma fase muito importante da vida do indivíduo.

O ser adolescente, de acordo com Bock, Furtado e Teixeira (2002), são construídos pela cultura. Várias sociedades exigem uma preparação para se entrar na vida adulta, assim tem-se o "adolescente", com suas características psicológicas que determinará esta fase. Papalia, Olds e Feldman (2009) contribuem dizendo que para entrar nesta fase, cada cultura tem seu modelo como ritual de maturidade, ou rito de passagem, ou ainda, pode se chamar de passagem para a idade adulta.

A adolescência então é uma fase de descobrimento do corpo e das emoções. "As mudanças corporais que ocorrem nesta fase são universais, com algumas variações, enquanto as psicológicas e de relações variam de cultura para cultura, de grupo para grupo e até de indivíduos de um mesmo grupo" (ZAGURY, 2002; p. 24).

Segundo Alves (2008), é neste período que se constrói a identidade, a individualização do sujeito do outro, e do espaço como "um só", em que surge o sentimento de saber "quem sou eu" e "a que grupo pertence" além da noção de ser portador de sua própria subjetividade. Com o tempo, os adolescentes vão se identificando com um grupo.

\footnotetext{
Na adolescência é a estrutura subjetiva que está em causa, devido ao abalo sofrido pelo imaginário. O jovem precisa emergir e sustentar-se, e necessita de outras referências além das parentais. (CAIROLE\& GAUER, 2009; p. 209).
}

Nesse contexto de construção de novos ideais, a principal referência se torna o grupo de amigos: os pares serão as grandes fontes de identificação deste momento.

De acordo com Carvalho e Colaboradores (2003), o adolescente vai buscar nas amizades a proteção que antes era cedida aos pais, pois sua maturação de "excriança" para "quase adulto" vai exigir uma proteção de seus temores e angústias. 


\section{HUM ANAS}

Conforme Papalia, Olds e Feldman (2009), para o adolescente conquistar autonomia e independência dos pais, eles se apóiam ao grupo de amigos, que é um espaço de experimentação, e no qual encontram afeto, solidariedade e compreensão.

Zagury (2002; p. 30) pontua que "as emoções são contraditórias. Deprimem-se com facilidade, passando de um estado meditativo e infeliz para outro pleno de euforia e crença em suas possibilidades". A autora salienta que, a busca pela identidade, precisa de um tempo, pois causa angústia, dificuldades de relacionamento, confusão e medo.

Neste contexto, segundo Tiba (2005), as características psicossociais surgem e vão sumindo à medida que os problemas são resolvidos; porém, os não resolvidos se acumulam nas etapas seguintes e é assim que a onipotência ${ }^{3}$ juvenil pode apresentar comportamentos de etapas anteriores e mesmo infantis. Bock e Colaboradores (2002; p. 297) explicam que psicologicamente o adolescente por não ser mais criança e ainda não ser adulto, vive a angústia que representa esta incerteza. "A tendência do jovem será no sentido de evitar a dissonância, procurando adequar essas contradições, ora evitando a norma do grupo juvenil, ora questionando os valores familiares".

Para Gregg e Shale (2003), a maioria dos adolescentes toma atitudes que os expõem ao perigo de forma a testar o mundo, e também, como marca para se separar dos pais. Bock e Colaboradores (2002) afirmam que a sociedade permite ao adolescente questionar, criar subculturas com seu linguajar e usar trajes característicos.

Desta maneira, Zagury (2002) evidencia que a busca pela identidade acarreta angústia, medo, confusão, dificuldades de relacionamento, ao mesmo passo que podem se sentir frágeis, instáveis emocionalmente e inseguros. Com tudo isso, o difícil mesmo, é viver com tanta contradição. Debortoli (apud Carvalho et al., 2003; p. 37), afirma que "a construção da identidade dos adolescentes é contraditoriamente uma identidade individual e uma identidade coletiva". Ao mesmo tempo em que o adolescente está para a sociedade, vive um impasse consigo mesmo, um período de transformações envolvendo a paz e a guerra que afloram entre as contradições.

\section{A internet}

A tecnologia com o passar dos tempos, aprimora-se cada vez mais. Tanto que hoje, boa parte da população pode ter acesso à internet. Contudo, é interessante conhecer uma breve história da evolução tecnológica até os dias atuais.

\footnotetext{
${ }^{3}$ Segundo Tiba (2005; p. 53), onipotência juvenil "uma das fases mais complicadas entre pais e filhos, muitos querem ter autonomia para escolher o seu programa em busca de adrenalina sem temer aos perigos".
} 


\section{A dependência dos adolescentes ao mundo virtual B.G. Gonçalves \& D. Nuernberg}

De acordo com Carvalho (2006), no período da II Guerra Mundial, ficou confirmado o desenvolvimento dos computadores eletrônicos, como ferramentas de processamento para cálculos matemáticos, principalmente na decifração de códigos criptografados, depois introduziram-se os computadores como máquinas de comunicação de controle de dados e informações. Desde então, a tecnologia foi melhorada, permitindo que computadores que pesavam muito, se tornassem equipamentos portáteis.

Castells (2006) relata que na década de 90, houve uma explosão de crescimento quanto à internet, abrindo espaço para usuários fora do meio acadêmico, e com o surgimento dos primeiros aplicativos de pesquisa de informações em rede. A comunicação virtual é um fenômeno social recente, com poucas pesquisas acadêmicas a respeito. Mas mesmo assim, já em 1990 se faziam debates sobre a dimensão social da internet. Argumentava-se que as comunidades virtuais podem levar o indivíduo ao isolamento, desatando vínculos das pessoas com a sociedade.

Tendo como base a rede, surge à internet como forma de interligar todas as redes em uma única, global, como descreveu Guizzo (2002), e salienta ainda que, as redes são vários computadores interligados em tempo real, capazes de trocar informações e recursos. Pellanda (2000; p. 141) sustenta que a rede possibilitou a incógnita de "como é possível o sermos onipotentes na internet?" A grandeza pode vir do fato da não identificação ou até mesmo pela falta de contato físico com o outro, o não olhar nos olhos.

Mas o que é internet? Para Castells (2004; p. 16), “a internet é um meio de comunicação que permite, pela primeira vez, a comunicação de muitos para muitos em tempo escolhido e a uma escala global". A internet se constitui em uma base de dados, capaz de transcender regras institucionais, além da liberdade de informação. Conforme Guizzo (2002), constituída por um grande número de redes, a internet é um sistema global de comunicação, através dos quais milhões e milhões de pessoas podem se comunicar, trocar informações, recursos e serviços. Além disso, seu meio de comunicação global permite ligar um computador do Brasil, por exemplo, para Inglaterra sem chamadas internacionais, diferentemente do sistema de telefonia.

Apesar da grande maioria da população mundial não ter acesso à rede, pode-se constatar que os ditos "excluídos digitais" (mesmo que indiretamente, usuários das lan- houses), já possuem certa dependência desta tecnologia. E assim são muitas as mudanças e impactos causados pela internet, na vida cotidiana das pessoas. Como diz Pellanda (2000; p. 129), "a internet é uma rede de interações de seres humanos propiciada pelo advento de uma tecnologia digital representada pelos computadores pessoais conectados em rede".

Segundo Lima e Colaboradores (2002), a internet é um meio sem limites para a circulação de informações, sejam elas governamentais, organizacionais ou pessoais, 


\section{HUM ANAS}

e em sua concepção, foi desenvolvida para garantir a segurança e proteção destas informações, mas nem sempre é real. Lévy (2000) declara que o computador pode auxiliar para o aprendizado e a aquisição de conhecimentos ou então, pode levar ao isolamento, e a separação de seus familiares e grupo social.

Porém, boa parte dos conteúdos da internet é necessária para a atualidade em que se vive, mas esta necessidade precisa ser averiguada. Investigar a frequência e a intensidade que se utiliza a internet se torna indispensável, pois o grande uso pode levar a um comprometimento na vida social da pessoa, podendo as relações de convívio real, aos poucos diminuírem e, assim o convívio virtual se tornará uma dependência.

Lévy (2000) assegura que qualquer pessoa ou um grupo, tendo ou não economias ou sendo de qualquer origem que for, pode investir em um ciberespaço, por conta própria, desde que tenha capacidades tecnológicas. Esta pessoa pode entrar em contato com outras, participar de comunidades ou até passar para a sociedade virtual, informações diversas de seu interesse. Já Castells (2004; p. 317) afirma que "a internet é, sem dúvida, uma tecnologia da liberdade, mas pode servir para libertar os poderosos e oprimir os desinformados", já que esta tecnologia exige um conhecimento para ser explorado.

Conforme Medeiros (2008), o adolescente através do ciberespaço pode realizar seus ideais, pode ser visto, pode ver e até se passar por outra pessoa, e assim os desejos de onipotência vão se concretizando. Pode-se dizer que a internet é um meio fácil, não só de expor os conteúdos desejados, como também de participar deles e pelo tempo almejado.

Medeiros (2008) argumenta que nas redes sociais da internet quanto mais amigos o adolescente tem, mais qualificações ele terá, ou seja, a amizade também é vista como mercadoria e algo de valor, como ser mais visível, mais famoso, mais popular. A autora salienta que através de sua pesquisa realizada com 473 alunos, ficou claro que o ato de acessar a rede social de internet, não se dá por meio de interação e contato, mas sim pelo fato de adicionar mais amigos. A amizade via internet não exige proximidade, isso pode fazer com que os adolescentes percam a relação com o outro através do toque, como um abraço, um beijo, um aperto de mão ou até mesmo um carinho.

Para Castells (2004), a internet é uma expansão da vida real, porém o que determina e define o uso de interação on-line, são as vidas reais. Leandro (2007) afirma que a utilização da internet se tornou indispensável nos dias de hoje e, além disso, esta utilização está tendo um vasto crescimento. Leandro (2007; p. 27) salienta ainda que "... na questão do entretenimento, também as pessoas já descobriram como buscá-lo na rede... O ser humano sente a necessidade de buscar sentido em tudo que faz, e não o consegue mantendo-se isolado socialmente". É através deste olhar que surge a questão em que "tudo que é demais não é bom", como ponto de partida para a dependência na adolescência. 


\section{A dependência dos adolescentes ao mundo virtual B.G. Gonçalves \& D. Nuernberg}

\section{Adolescência e o espaço virtual}

Nardon (2006) explica que é na adolescência, que o convívio social se amplia, com a participação nos diferentes grupos, aos quais os adolescentes pertencem, como: escola, esportes, cursinhos, lazer, entre outros. Porém, nem sempre é assim, o que deveria ser uma relação de afetividade e encontro com grupos do mesmo interesse, fica em alguns casos a mercê da era digital.

De acordo com Fonte (2008), quando o adolescente faz o acesso à internet não supervisionado, pode tornar-se mais do que um meio de informações a conteúdos culturais, ou seja, pode vir a tornar-se um fator desestruturante no processo sócio-emocional deste adolescente. Lévy (2000; p. 214) reconhece que há dependentes na internet que passam horas em frente ao computador, participando de salas de bate-papo, de jogos on-line ou até mesmo, "surfando interminavelmente de página em página".

Fonte (2008) orienta que a utilização da internet, faz com que o adolescente consiga fazer contatos pessoais que fora deste meio não consegue, assim formando contatos "superficiais" e de "falsa intimidade", facilitando para o afastamento social. Nardon (2006) expõe que os adolescentes, que estabelecem um bom relacionamento social, têm mais possibilidades de construírem um bom desenvolvimento psicossocial. Sendo assim, o uso contínuo da internet faz com que os adolescentes não se desenvolvam com plenitude, podendo ter dificuldades relacionais na vida adulta.

Lévy (2000; p. 234) diz que: "as potencialidades positivas da cibercultura ${ }^{4}[\ldots]$ em nada garantem a paz ou a felicidade. Para, que se tornem mais humanos é preciso suscitar a vigilância, pois o homem sozinho é inumano, na mesma medida de sua humanidade". Desta forma, um movimento de cautela em relação à internet é importante para a segurança dos adolescentes, evitando assim a sua dependência.

De acordo com Fonte (2008), são vários os indícios que mostram a dependência do adolescente. Os principais são: preocupação com a internet quando está off-line; necessidade contínua de usar a internet; necessidade de usar a internet para fugir dos problemas, como insegurança, culpa e ansiedade. Mentir para as pessoas como forma de encobrir o uso da internet; comprometimento social e motor; sensação de estar vivendo um sonho ao utilizar a internet; duração de tempo maior que seis meses.

Leitão e Costa (2005) orientam que a internet faz gerar a sensação de poder tudo, até ignorar limites do mundo real, já que os usuários podem manter o anonimato, o acesso fácil às informações e a realização de diferentes atividades.

\footnotetext{
${ }^{4}$ Segundo Lévy (2000; p. 17), cibercultura designa "o conjunto de técnicas (materiais e intelectuais), de práticas, de atitudes, de modos de pensamento e de valores, que se desenvolvem juntamente com o crescimento do ciberespaço".
} 


\section{HUMANAS}

Além disso, as autoras descrevem três tipos de excesso no uso da internet: o grande número de informações, a quantidade de horas que permanecem conectados e a exposição excessiva da intimidade. São processos que o adolescente passa, e em alguns casos, sem o contato com a família, pode levar a dependência.

Os benefícios encontrados na rede social são vários como: aumento do número de informações, para utilização no meio escolar e em grupos de amigos, favorece o contato indireto com pessoas com assuntos de seu interesse, aumenta o número de amigos conforme (FONTE, 2008). A autora também descreve os malefícios encontrados na internet, como: pornografias, conteúdos violentos, a possibilidade de encontrar pessoas pouco convenientes.

Para Caetano e Colaboradores (2010), os malefícios encontrados na internet são: o cyberbulliyng; que pode durar todo o tempo, já que envolve a tecnologia e esta pode ser executada, através de mensagens; perda da privacidade e o risco de ser encontrado; pois nos perfis estão dados pessoais, recebimento de material pornográfico e/ou violento, ser vítima de fraude, além dos vírus. A internet é um meio de comunicação e por isso há a possibilidade de serem encontradas informações com conteúdos como no mundo real, sejam eles positivos ou negativos.

Nardon (2006) salienta que através do ciberespaço, o processo natural do adolescente ao convívio social, um dos mais importantes para o desenvolvimento psicológico e social do adolescente, torna-se virtual. É a partir disso, que profissionais da área devem estudar os aspectos da dependência pelo espaço democrático que é a internet, e todos os meios que ela traz.

Leandro (2007) explica que os adolescentes adictos na internet vão necessitar de ajuda terapêutica. E o tratamento em alguns casos, inclui o uso de medicamentos, parecido aos casos de vícios de álcool e drogas, em que o paciente deve aceitar a dependência. Ao uso contínuo da internet podem-se encontrar diversos tipos de problemas psicológicos, como: timidez, pânico e fobia social, isolamento social, transtorno afetivo, depressão.

Nessa etapa do desenvolvimento, se inicia o processo de relacionamentos afetivos. (NARDON, 2006). Assim como a sociedade contemporânea, os relacionamentos sociais entre os adolescentes estão sempre passando por mudanças. Com tantas modificações, os adolescentes ficam inseguros no momento da escolha de um relacionamento interpessoal. E é assim, que se percebem sentimentos, como: timidez e vergonha.

Leitão e Costa (2005; p. 444) ressaltam um ponto em comum em sua pesquisa com psicoterapeutas que já atenderam ou atendem pacientes com dependência na internet: "no atendimento de usuários da internet, os psicoterapeutas depararam-se com uma descoberta: a Rede é, para muitos pacientes, uma nova fonte de prazer e um agradável espaço de vida, 


\section{A dependência dos adolescentes ao mundo virtual B.G. Gonçalves \& D. Nuernberg}

no qual se relacionam com outras pessoas". Porém, o comportamento dessas pessoas fica limitado ao uso excessivo da internet, e sendo assim, como que se procede ao lado familiar, profissional, de lazer, hobbies, entre outros, onde o convívio, o olhar nos olhos, o toque ficam? Eis uma questão que deve ser levada em consideração pelo fato de o ser humano, como já dizia Lévy (2000; p. 234), "sozinho ser inumano".

\section{Método e análise de dados}

Esta pesquisa tem por objetivo principal investigar as correlações da dependência pela internet com as interferências e problemas que isso pode gerar nos adolescentes. Sendo assim, buscou-se analisar este tema, através de uma pesquisa de campo aplicada, interpretando cada questão obtida pelos adolescentes.

A população desse estudo é composta por 10 alunos (5 adolescentes do sexo feminino e 5 adolescentes do sexo masculino). Para a coleta de dados foi utilizada uma entrevista semiestruturada com perguntas baseadas nos objetivos do referido estudo. A coleta de dados teve como instrumento a entrevista semiestruturada, sendo aplicada aos alunos voluntários do $1^{\circ}$ ano do Ensino Médio do Colégio de Aplicação da UNESC, Criciúma/SC. E de acordo com Neto (apud MINAYO, 2009; p. 57) "a entrevista é o procedimento mais usual no trabalho de campo e pode ser coletiva ou individual". Desta maneira, já que os adolescentes que participaram da pesquisa são menores de idade, foi realizado um termo de autorização para os pais, e mantido os sigilos, conforme as normas éticas. Assim, sendo aprovado pelo comitê de ética da UNESC, pelo parecer número 141/2011.

A partir do levantamento foi possível averiguar com relação à idade dos adolescentes participantes que, 7 estão com 14 anos (três do sexo masculino e quatro do sexo feminino), 2 estão com 15 anos (um do sexo masculino e um do sexo feminino) e 1 não colocou a idade (sexo masculino). De acordo com o dicionário Michaelis (2008) e Bock e Colaboradores (2002), adolescência é o período da vida humana que vai da puberdade à idade adulta, estendendo-se dos 10 aos 19 anos, com isto a pesquisa se direcionou aos adolescentes de 14 e 15 anos.

Observou-se que quando a pesquisa aborda o tempo em que costuma ficar na internet durante o dia, surgiram respostas diversificadas como:

Adolescente A: "durante a semana umas 8 horas, em finais de semana 14 horas".

Adolescente B: "mais ou menos 10 horas por dia". Adolescente C: "3 horas".

Adolescente D: "dia de semana umas 5 horas, fim de semana 7 horas".

Adolescente E: "5 horas". 
Adolescente F: "finais de semana: 14 a 16 horas, dias de semana: 5 a 7 horas".

Adolescente G: "13 horas".

Adolescente H: "dia de semana 8 horas, final de semana cerca de 11 horas".

Adolescente I: "em média de 10 a 12 horas por dia, sábado eu fico 24 horas".

Adolescente J: "mais ou menos umas 11 horas".

Comparando com o tempo que tem um dia, ou seja, 24 horas, muitos destes adolescentes utilizam seu tempo livre para a navegação na internet. Graeml e Colaboradores (2004), citam na revista Young, que em seus estudos conseguiram identificar dois tipos de usuário: os dependentes de internet e os não dependentes de internet. E destacaram que os dependentes utilizam em média de 38,5 horas on-line por semana para uso de natureza não profissional. Além disso, relataram aumento gradual do uso da internet durante a pesquisa.

Quando questionados sobre o que mais utiliza na internet, optaram por escolher várias alternativas, ou seja, dos 10 adolescentes, 9 assinalaram em redes sociais, 8 músicas, 6 jogos, 5 para chats, 5 pesquisas, 2 sites relacionados com sexo, 1 fóruns, 1 notícias do mundo, 1 chamada de voz e 1 seriados.

Fonte (2008) destaca que a utilização da internet faz com que o adolescente consiga realizar contatos pessoais que fora deste meio não conseguiria, assim formando contatos "superficiais" e de "falsa intimidade", facilitando para o retraimento social.

Para Graeml e Colaboradores (2004), as pessoas podem estar mais confiantes em participar de chats para satisfazer suas necessidades de base social, pelas dificuldades que apresentam para estabelecer contatos na vida real, quando confrontadas à facilidade proporcionada pelo ambiente de um chat.

Epstein (2007) argumenta que todos os dias, no mundo todo, centenas de milhões de pessoas acessam a rede mundial da internet em busca de parceiros e companhia. Salas de bate-papo, redes sociais, sites de relacionamentos, comunidades virtuais. Isso significa que a pessoa amplia suas relações no mundo virtual, enquanto que o contato físico fica a mercê da era digital e acaba por não acontecer.

Em sequência foi questionado em quais redes sociais tem perfil e por $q u \hat{e}$. As redes sociais mais citadas foram: os 10 adolescentes citaram Orkut, 8 Messenger, 7 Twiter e 7 Facebook. Algumas respostas dos participantes:

Adolescente B: “... São os espaços onde eu me comunico com pessoas, até desconhecidos".

Adolescente D: "Porque quando estou conectado com essas redes sociais me sinto mais próximo do mundo atual". 


\title{
A dependência dos adolescentes ao mundo virtual B.G. Gonçalves \& D. Nuernberg
}

\begin{abstract}
Adolescente J: "Porque gosto de estar em contato com todos os meus amigos, por várias horas do dia, sabendo e contando novidades, programando festas, gosto também de estar postando fatos e comentando sobre os outros, falando sobre o meu dia-a-dia..."
\end{abstract}

Nas redes sociais da internet quanto mais amigos o adolescente tem, mais qualificações terá, ou seja, a amizade também é vista como mercadoria e algo de valor, como ser mais visível, mais famoso, mais popular (MEDEIROS, 2008).

As redes sociais ou sites de relacionamentos foram criados com a ideia de reunir amigos através da internet, onde você pode trocar todos os tipos de arquivos e informações com seus amigos e também com desconhecidos. A maioria dos jovens possui uma conta em um ou mais sites. Fazendo parte de suas rotinas escreverem scraps (recados) a seus amigos, adicionarem nestes sites fotos da festinha do fim de semana, ou mesmo manterem contato constante com amigos (as) e namorados (as) (TICIANELLI, 2009; p. 43).

Pirolo e Colaboradores (2009) acrescentam que a internet modifica o termo amizade, que não representa somente quantidade, visto que se torna cada dia menor, o número de amizades que permitem o contato físico; assim as preferências e escolhas ficam ligadas ao mundo virtual e visível a quem puder e quiser ver.

A próxima questão referiu-se a rede social que mais gosta e por quê. A prevalência foi twitter e orkut com 5 opiniões cada, sendo que messenger obteve 1 opinião e um adolescente comentou que não gosta de redes sociais.

Adolescente B: "Twitter, pois é onde eu falo o que gosto, cito o que quero e falo o que penso".

Adolescente E: "Orkut, pois há inúmeros atrativos legais e consigo ver o que meus amigos fazem". Adolescente F: "Msn: posso me comunicar com meus amigos a qualquer momento".

Adolescente H: "Gosto do Twitter porque lá consigo na maioria das vezes, expressar o que eu sinto, sem medo, e também encontro várias pessoas com quem me identifico e começo novas amizades. É uma espécie de intercâmbio." 


\title{
H UM ANAS
}

Para Zagury (2002), na adolescência, juntamente ao desenvolvimento físico interno e externo, ocorrem modificações em nível social. Os grupos de amigos tendem a aumentar e a imitação define-se novamente, sendo influenciado pelo grupo e agindo da mesma forma para se sentir pertencente ou identificar-se a um determinado grupo social.

Castells (2004) informa que as redes surgem a partir das escolhas de quem a faz, tornando como formas principais de sociabilidade. As pessoas em rede podem mudar de interesse sem precisar de sua verdadeira identidade, como também podem usar como modo de manifestação. Porém, as sociedades ligadas por computador contribuem para o individualismo em rede, podendo construir comunidades virtuais e não físicas.

Sobre o fato de terem perfil fake (falso) na internet e o porquê, verificou-se que dos dez adolescentes pesquisados, cinco responderam que tem ou tiveram e cinco adolescentes responderam que não tem perfil fake na internet.

\begin{abstract}
Adolescente E: "Não, acho ridículo fingir ser outra pessoa".

Adolescente G: "Sim, porque eu gosto de hackear outras redes".

Adolescente H: "Já tive, muitas vezes (como era o meu caso), a pessoa quer se expressar e dizer o que pensa, mas tem medo do que os outros vão achar sobre isto, então cria um perfil fake".

Adolescente J: "Há mais ou menos seis anos atrás quando ganhei o meu primeiro computador e comecei com o uso da internet meus pais não autorizaram a minha participação de alguma rede social, por isso faziam o incentivo de que eu tivesse perfis fake para poder conversar com meus amigos, mas hoje não tenho nenhum, até porque não acho legal esse tipo de prática. Somo o que somos."
\end{abstract}

Em Gregg e Shale (2003) encontra-se que a maioria dos adolescentes tomam atitudes que os expõem ao perigo, de forma a testar o mundo e também como marca de se separar dos pais.

Conforme Medeiros (2008), o adolescente através do ciberespaço pode realizar seus ideais, pode ser visto, pode ver e até se passar por outra pessoa, e assim os desejos de onipotência vão se concretizando. Pode-se dizer que a internet é um meio fácil não só de expor os conteúdos desejados, como também, de participar deles e pelo tempo almejado.

$\mathrm{Na}$ questão que tratava sobre $o$ que mais gosta na internet, obtiveramse respostas diversas, porém a maioria dos adolescentes argumentou preferir o diálogo com os "amigos." 


\title{
A dependência dos adolescentes ao mundo virtual B.G. Gonçalves \& D. Nuernberg
}

\begin{abstract}
Adolescente A: "Poder se comunicar com outras pessoas, algumas que até nem conhecemos". Adolescente F: "Ficar sabendo de coisas que não aparecem na TV, me expressar, já que a TV manipula muito as pessoas".

Adolescente H: "Conhecer pessoas novas, saber/ aprender coisas que eu nem imaginaria".

Adolescente I: “... Ver séries e filmes”.

Adolescente J: "Das redes sociais, pois são nelas que passo cerca de 11 a 12 horas do meu dia e garanto que se pudesse ficar mais, com certeza eu ficaria".
\end{abstract}

Os benefícios encontrados na rede social são vários como: aumenta o número de informações, para utilização no meio escolar e em grupos de amigos, favorece o contato indireto com pessoas com assuntos de seu interesse, aumenta o número de amigos. Contudo, encontram-se também os malefícios, tais como: pornografias, conteúdos violentos, a possibilidade de encontrar pessoas pouco convenientes entre outros (FONTE, 2008).

Nardon (2006; p. 32) defende a ideia da relação de afeto se tornar cada vez mais escassa, ou seja, fazendo com que as relações com os amigos se tornem "frias", pois os amigos passam a se comunicar através da internet e não mais "ao vivo". E mais uma vez, a questão da dependência pela internet mostra o quanto o adolescente pode deixar de se relacionar com seus amigos.

No que diz respeito ao tempo que consegue ficar sem internet, a maioria dos adolescentes colocaram pouco tempo.

Adolescente B: "Muito pouco tempo, eu fico agoniada quando estou sem internet e não paro até me conectar a ela, independente no computador ou no celular".

Adolescente D: "Só fico sem net quando estou na aula, chego em casa a primeira coisa é ligar o PC, ficar sem net realmente não dá”.

Adolescente H: “... Muito pouco tempo, no computador nem tanto, mas tem o celular que acessa a internet, ou seja, a qualquer lugar que eu vá eu consigo entrar na internet, o tempo que eu fico sem internet é basicamente o tempo em que eu fico na escola".

Adolescente I: "Se eu estiver viciado em algum jogo nem consigo dormir direito". 


\title{
HUM AN AS
}

De acordo com Fonte (2008), são vários os indícios que mostram a dependência do adolescente. Os principais são: preocupação com a internet quando está off-line; necessidade contínua de usar a internet; necessidade de usar a internet para fugir dos problemas, como insegurança, culpa e ansiedade. Mentir para as pessoas como forma de encobrir o uso da internet; comprometimento social e motor; sensação de estar vivendo um sonho ao utilizar a internet.

Leitão e Costa (2005) descrevem três tipos de excesso ao uso da internet: ao grande número de informações, o número de horas que permanecem conectados e a exposição excessiva da intimidade. São processos que o adolescente passa e em alguns casos sem o contato com a família leva a dependência.

Quando perguntado se a internet é fundamental ou pode ser eliminada de sua vida, os adolescentes foram unânimes em dizer que é fundamental.

\begin{abstract}
Adolescente B: "Penso que muitos benefícios ela não me traz, é algo que eu uso muito, até muitas vezes, deixo de comer porque estou na internet. Eu até já tentei ficar sem a internet, mas já se tornou algo automático, chego do colégio, almoço, arrumo umas coisas e depois direto para internet onde fico até 22 horas".

Adolescente J: "Em minha vida ela é fundamental, pena que gerou um enorme vício que é muito difícil de ser contido, dependo dela para muitas coisas em meu dia-a-dia, e quando passo um ou dois dias sem o contato já me sinto 'perdida na sociedade' pode-se dizer".
\end{abstract}

Fonte (2008; p. 15) declara que sobre a internet com seus riscos e oportunidades se deve levar em consideração somente uma coisa: "a internet em si mesma não é boa nem má, depende do uso que se faça dela". Para Castells (2004), a internet é uma expansão da vida real, porém o que determina e define o uso de interação on-line, são as vidas reais.

Leitão e Costa (2005; p. 444) ressaltam um ponto em comum em sua pesquisa com psicoterapeutas que já atenderam ou atendem pacientes com dependência na internet: "no atendimento de usuários da internet, os psicoterapeutas depararam-se com uma descoberta: a rede é, para muitos pacientes, uma nova fonte de prazer e um agradável espaço de vida, no qual se relacionam com outras pessoas".

Com isso pode-se ressaltar que como o vício por drogas ou álcool, agrada a quem usar, o mesmo acontece com o dependente pelo mundo virtual e esta dependência, com o tempo, trará dificuldades para quem faz o uso contínuo. 


\section{A dependência dos adolescentes ao mundo virtual B.G. Gonçalves \& D. Nuernberg}

A internet é um meio de comunicação e possibilidades de informações, que podem ser encontrados conteúdos como no mundo real, sejam eles positivos ou negativos, e vai depender (como o próprio nome já diz) de quem a utiliza, ficar dependente/sujeitado do mundo virtual.

\section{Considerações finais}

A partir do estudo realizado, observou-se que a internet no contexto atual pelas suas características interacionais com o mundo virtual e dinâmico das informações, torna-se, muitas vezes, objeto de dependência entre os adolescentes.

Nesse contexto, corrobora-se com Leitão e Costa (2005) e com a maioria dos pesquisadores que trataram do tema, de que a internet faz gerar a sensação de ter poder e acesso a tudo e até de ignorar limites do mundo real, já que os usuários podem manter o anonimato, o acesso fácil às informações e a realização de diferentes atividades.

As características peculiares da adolescência potencializam ao jovem um encontro mais imediato com aquilo que almejam na busca de sua autoafirmação enquanto indivíduos que precisam do outro para formar sua identidade, no qual aspectos como número de amigos, identificação com os grupos de interesses, manter-se atualizado com o grupo de amigos e se sentir em um espaço mais amplo, contribuem para que os adolescentes fiquem cada vez mais na frente da tela de um computador. É importante aqui também salientar que a maioria dos adolescentes tomam atitudes que os expõem ao perigo de forma a testar o mundo e também como marca de se separar dos pais.

A partir dos dados da pesquisa pode-se constatar que a dependência pela internet ocorre porque o ciberespaço permite experiências que na vida real muitas vezes, seriam frustrantes para o adolescente, como a aceitabilidade pelo grupo, os conhecimentos de interesse, o número de amigos, o acesso rápido a interações como jogos, salas de bate-papo e até mesmo a super exposição nas redes sociais que acentuam o ego dos adolescentes e os fazem sentirem-se mais conectados com os amigos e com o mundo.

O adolescente, através do ciberespaço, pode realizar seus ideais, pode ser visto, pode ver e até se passar por outra pessoa, e assim os desejos de onipotência vão se concretizando. Pode-se dizer que a internet é um meio fácil, não só de expor os conteúdos desejados como também de participar deles e pelo tempo almejado (MEDEIROS, 2008).

Nesse viés, a internet é vista como um meio de comunicação e possibilidades de informações, na qual podem ser encontrados conteúdos como no mundo real, sejam eles positivos ou negativos. Para os adolescentes é importante estar conectado, pois no universo da internet conseguem, 


\section{HUM ANAS}

mesmo que fantasiosamente, serem únicos, muitas vezes, fazem uma projeção daquilo que almejam, conforme visto na pesquisa, com a utilização de perfis fakes - falsos.

Os problemas relativos à adicção na internet se manifestam na falta de interação com o outro no mundo real, pois a tela do computador traz segurança aos adolescentes, assim evitam-se frustrações, rejeições, sentimentos que encontrariam na vida real e teriam de enfrentar. Desta forma, pode-se dizer que a internet serve como uma fuga da realidade muitas vezes, e, dependendo do nível da fuga, essa dependência precisa de tratamento, principalmente, quando interfere diretamente na qualidade de vida do adolescente.

Para tanto, é de extrema importância a participação da família neste viés. Mesmo que na fase da adolescência seja natural que o adolescente busque ouvir mais os amigos, o diálogo com a família faz com que ele enxergue questões futuras e norteadoras para a sua segurança, como a conscientização pelo uso/tempo correto da internet, sendo que para isso muitos pais também precisam estar conscientes de como funciona o mundo virtual. E para isto, seria necessário um trabalho de conscientização nas escolas, depoimentos de pessoas com conhecimento na área, informação em mídia falada e escrita como forma de prevenir e auxiliar ao familiar, o adolescente e professores.

Portanto, a internet cresce em ritmo acelerado e com isto muitos buscam se manterem atualizados com a nova era. Então ficam estas reflexões acerca do mundo virtual como um alerta para oportunizar-se uma adolescência saudável.

\section{Referências bibliográficas}

ALVES, G.M. A construção da identidade do adolescente e a influência dos rótulos na mesma. Trabalho de Conclusão de Curso. Criciúma: Curso de Psicologia, Universidade do Extremo Sul Catarinense, 2008.

BOCK, A.M.B.; FURTADO, O. \& TEIXEIRA, M. de L.T. Psicologias: uma introdução ao estudo de psicologia. 13a Edição. São Paulo: Saraiva, 2002.

CAETANO, H.; MIRANDA, G. L. \& SOROMENHO, G. Comportamentos de risco na internet: um estudo realizado numa escola do ensino secundário. Revista Latinoamericana de Tecnología Educativa, 9(2): 167-85, 2010.

CAIROLI, P. \& GAUER, G.J.C. A adolescência escrita em blogs. Estudos de Psicologia (Campinas): 26(2): 205-13, Junho de 2009. 
CARVALHO, A.M.; SALLES, F. \& GUIMARÃES, M.M. Adolescência. Belo Horizonte: Instituto de Filosofia e Teologia de Goias, 2003.

CARVALHO, M.S.R.M. de. A trajetória de Internet no Brasil: do surgimento das redes de computadores à instituição dos mecanismos de governança. Rio de Janeiro, 2006 (http://www.nethistory.info/Internet-BR-DissertacaoMestrado-MSavio.pdf).

CASTELlS, M. A sociedade em rede. 9a Edição. São Paulo: Paz e Terra, 2006.

CASTELLS, M. A galáxia internet: reflexões sobre internet, negócios e sociedade. Lisboa: Fundação Calouste Gulbenkian, 2004.

EPSTEIN, R. Paraíso da enganação. Viver Mente \& Cérebro, 14(171): 94-97, 2007.

FONTE, L. A influência das novas formas de comunicação no desenvolvimento sócio-emocional das crianças. Disponível em: [www.psicologia.com.pt/ artigos/textos/A0405]. Acesso em 2008.

GRAEML, K.S.; VOLPI, J.H. \& GRAEML, A.R. O impacto do uso (excessivo) da Internet no comportamento social das pessoas. Revista Psicologia Corporal (José Henrique Volpi e Sandra Mara Volpi, Orgs.), volume 5, 2004.

GREGG, M.C. \& SHALE, E. Criando adolescentes: como prepará-los para os desafios da vida. São Paulo: Fundamentos Educacionais, 2003.

GREGORIM, C.O. (Ed.). MICHAELIS: Dicionário prático da língua portuguesa. São Paulo: Editora Melhoramentos, 2008.

GUIZZO, E. Internet: o que é, o que oferece, como conectar-se. São Paulo: Ática, 2002.

LEANDRO, D.R. O universo multimídia e a Psicologia: um diálogo entre a tecnologia e o emocional humano. Trabalho de Conclusão de Curso. Criciúma: Curso de graduação em Psicologia, Universidade do Extremo Sul Catarinense, 2007.

LEITÃO, C.F. \& COSTA, A.M.N. da. Impactos da Internet sobre pacientes: a visão de psicoterapeutas. Psicologia em Estudo (Maringá), 10(3): 441-50, 2005.

LÉVY, P. Cibercultura. São Paulo: Editora 34, 2000. 


\section{HUMANAS}

LÉVY, P. O que é o virtual? São Paulo: Editora 34, 1997.

LIMA, G.; PINTO, L. \& LAIA, M. Tecnologia da Informação: impactos na sociedade. Disponível em: [http://www.uel.br/revistas/]. Acesso em 2002.

MEDEIROS, R. de A. A relação de fascínio de um grupo de adolescentes pelo orkut: um retrato da modernidade líquida. Dissertação de mestrado. Programa de Pós-Graduação em Educação, Faculdade de Educação da Universidade de São Paulo, 2008.

MINAYO, M.C. de S. O desafio da pesquisa social In: M.C. de S. MINAYO (Org). Pesquisa social: teoria, método e criatividade. $28^{a}$ Edição. Petrópolis: Vozes, 2009.

NARDON, F. A relação interpessoal dos adolescentes no mundo virtual e no mundo concreto. Trabalho de Conclusão de Curso. Criciúma: Curso de graduação em Psicologia, Universidade do Extremo Sul Catarinense, 2006.

PAPALIA, D.E.; OLDS, S.W. \& FELDMAN, R.D. Desenvolvimento humano. $9^{a}$ Edição. Porto Alegre: Artmed, 2009.

PELLANDA, N. \& PELLANDA, E.C. Ciberespaço: um hipertexto com Pierre Lévy. Porto Alegre: Artes e Ofícios, 2000.

PIROLO, M.A.M.; FORTES, W.G.; DALMAS, J.C. et al. As redes de relacionamentos e seus reflexos na interação social do jovem. Intercom - Sociedade Brasileira de Estudos Interdisciplinares da Comunicação. Blumenau: X Congresso de Ciências da Comunicação na Região Sul, 28 a 30 de Maio de 2009.

TIBA, I. Adolescente: quem ama, educa! São Paulo: Integrare, 2005.

TICIANELLI, A.S. Protegendo seus filhos no uso da Internet. Escola Superior de Redes RNP. Versão 1.0.0. Disponível em: [http://www. esr.rnp.br]. Acesso em 2009.

ZAGURY, T. $O$ adolescente por ele mesmo. 13 ${ }^{\text {a }}$ Edição.Rio de Janeiro: Record, 2002. 